\title{
ВИКОРИСТАННЯ SIMАРRО 8 ДЛЯ ПОРІВНЯЛЬНОГО АНАЛІЗУ ВПЛИВУ РІЗНИХ ТИПІВ АВТОМОБІЛІВ НА ДОВКІЛЛЯ
}

\begin{abstract}
Проаналізовано екологічні проблеми, котрі пов'язані із автомобільною галуззю, зокрема транспортування. Грамотному прийняттю рішень щодо покращення екологічних аспектів транспортних засобів для державного чи приватного бізнесу допомагає такий інструмент екологічного менеджменту як Оцінка Життєвого Циклу. Цей метод полягає у визначенні усіх чинників впливу на стан навколишнього природного середовища на кожному етапі виробництва продукції. Здійснено експериментальні дослідження щодо визначення впливу на довкілля автомобілів із бензиновим двигуном (СВРО-3 та ЄВРО-5) та електромобілем (Tesla Semi) завдяки сертифікованій комп'ютерній програмі з екологічного моделювання SimaPro 8 в режимі роботи "Invenatary". Проведено розрахунок за допомогою алгоритму LCA Wizard, який є розробкою компаніï "PRé Sustainability". Результатами цього моделювання стали оцінки в Impact Points, згідно зі значеннями яких використання електричних агрегатів $\epsilon$ ефективнішим в 1,73 раза порівняно зі стандартом палива СВРО-3 та в 1,53 - порівняно зі стандартом палива ЄВРО-5, навіть за умови використання ідентичного типу викопного палива. Визначення впливу на категорії, а саме: Здоров'я суспільства; Якість екосистем; Зміна клімату; Ресурси - допомагатиме здійснити оцінку загального впливу на стан навколишнього середовища на будь-якій стадії автомобілебудування, експлуатації та споживання енергоресурсів.
\end{abstract}

Ключові слова: Оцінка Життєвого Циклу; SimaPro; моделювання; транспортний засіб.

Вступ. Автомобілебудування є одним із великих ресурсомістких галузей промисловості. Користування автомобільним транспортом характеризується значним впливом на стан навколишнього середовища. Відпрацьовані гази двигуна внутрішнього згоряння автомобіля містять досить великі кількості токсичних речовин, зокрема оксиди вуглецю, азоту та сірки. Це призвело, по-перше, до збільшення парникового ефекту з подальшою незворотною зміною клімату i, по-друге, до зниження імунітету багатьох людей внаслідок порушення основ генетичної спадковості. Уряди країн на законодавчому рівні змушують виробників удосконалювати бензинові двигуни для зниження рівня токсичних вихлопів (стандарти ЄВРО 1-6), а також до необхідності пошуків альтернативних шляхів розвитку транспортних технологій та підходів їх застосування.

Одним із таких напрямків вирішення перерахованих завдань $\epsilon$ виробництво електромобілів. Це перша технологія, яка офіційно отримала статус нульового викиду, і вона вже представлена на ринку. Поширення електромобілів стримується дефіцитом акумуляторів і їх високою ціною. Ведуть роботи над створенням акумуляторних батарей з малим часом зарядки (близько 15 хв), зокрема і зі застосуванням наноматеріалів. Розглядають також можливість використання як джерела струму не акумуляторів, а іоністорів (суперконденсаторів), що мають дуже малий час зарядки, високу енергоефективність (понад $95 \%$ ) і набагато більший ресурс циклів "зарядка-розрядка" (до декількох сотень тисяч).

Актуальність тематики дослідження. Одним із методів попередження і зниження негативного впливу виробництва на стан довкілля є метод "Оцінки Життєвого Циклу", який сформувався в період 1970-1990тих років, пройшовши етапи стандартизації інструментарію, термінології, досягнення конкретних і виразних результатів досліджень. Дослідження, присвячені застосуванню інструментів оцінки життєвого циклу для аналізу стійкого розвитку та регіональних систем управління відходами, виконано в працях закордонних вчених, таких як: У. Гелбман (U. Gelbmann), Х. Горрард (H. Gorrard), Х. Клампфл-Пернольд (H. Klampfl-Pernold), а також у роботах вітчизняних учених щодо інструментів для оцінки екологічного впливу, зокрема О. Балацького, О. Веклич, Г. Виговської, Т. Галушкіної, Л. Мельника, В. Міщенка, Н. Пахомової, І. Синякевича, П. Скрипчука та ін. (Frolov \& Bilopilska, 2013).

Цей метод полягає в інвентаризації усіх можливих впливів впродовж життєвого циклу продукції ("від колиски до могили") на такі категорії як здоров'я суспільства, споживання ресурсів, якість екосистеми, зміна клі-

\section{Інформація про авторів:}

Одноріг Зоряна Степанівна, канд. техн. наук, доцент, кафедра екології та збалансованого природокористування. Email: odnorigzor@gmail.com; https://orcid.org/0000-0003-3011-4845

Тимчук Іван Степанович, канд. с.-г. наук, асистент, кафедра екології та збалансованого природокористування. Email: i.s.tymchuk@gmail.com; https://orcid.org/0000-0001-9344-3035

Жидун Василь Іванович, магістрант, кафедра екології та збалансованого природокористування. Email: vasil.zhidun@gmail.com

Цитування за ДСтУ: Одноріг 3. С., Тимчук І. С., Жидун В. І. Використання Simapro 8 для порівняльного аналізу впливу різних типів автомобілів на довкілля. Науковий вісник НлтУ України. 2018, т. 28, № 11. С. 64-67.

Citation APA: Odnorih, Z. S., Tymchuk, I. S., \& Zhydun, V. I. (2018). Use of Simapro 8 for comparative analysis of the influence of different vehicle types on the environment. Scientific Bulletin of UNFU, 28(11), 64-67. https://doi.org/10.15421/40281112 
мату. ОЖЦ узгоджується стандартами ISO 14040:2006 "Екологічне керування. Оцінка життєвого циклу. Принципи та структура" та ISO 14044:2006 "Екологічний менеджмент. Оцінка життєвого циклу. Вимоги та рекомендації", які в системі екологічного менеджменту серії ISO 14000 вимагають приймати управлінські рішення на кожному етапі виробництва продукції.

Управління життєвим циклом (LCM) - це збір адміністративної системи, що структурує пов'язану із продуктом інформацію від різних програм та аналітичних інструментів, які об'єднують екологічні, економічні та соціальні аспекти в життєвий цикл. До інструментів належать (Berzina et al., 2017):

- Оцінка життєвого циклу (LCA);

- Вартість життєвого циклу (LCC);

- Аналіз витрат і прибутку (CBA);

- Аналіз потоків сировини та матеріалів (SFA/MFA);

- Аналіз вхідних/вихідних потоків продукційної системи (IOA);

- Споживання матеріалу на одиницю продукції (MIPS);

- Кумулятивний аналіз енергоспоживання (СЕРА);

- Оцінка більш чистого виробництва (CРА);

- Оцінка ризику (RA).

ОЖЦ оцінює екологічну ефективність таких показників, як пряма або питома кількість використаних коштів, матеріалів та ресурсів, споживання енергії, визначає потоки викидів, скидів та відходів. Важливо усвідомити, що моделювання є спрощеним і не відтворює реальність повністю, тобто в дійсності ситуація може дещо спотворитися. Фахівець повинен розробляти модель таким способом, щоб спрощення та спотворення не мали вагомого впливу на кінцевий результат. Завдяки цьому виробник має змогу чітко визначити цілі і задачі, сформувати екологічну політику, врахувати екологічні аспекти товарів і послуг.

Мета дослідження - провести власні експериментальні дослідження щодо визначення впливу на довкілля автомобілів із бензиновим та електродвигуном завдяки моделюванню методом Оцінки Життєвого Циклу. Результатом досліджень буде підтвердження ефективності того чи іншого варіанта автомобілів. Методи дослідження: аналітичний (аналіз баз даних Ecoinvent v.3.0 за допомогою програмного забезпечення для ОЖЦ як "Umberto-LCA+", "GaBi Software LCA" та "SimaPro"); лабораторний. Для програмного розрахунку ОЖЦ обрано ліцензійну комп'ютерну програму з екологічного моделювання SimaPro 8. Дослідження проведено в комп'ютерній лабораторії кафедри екології та збалансованого природокористування Національного університету "Львівська політехніка".

Для порівняльної характеристики вибрано 3 екземпляри модельованих транспортних засобів однакового тоннажу та відстані пересування. Конкретні моделі тягачів ЄВРО-3 та ЄВРО-5 не потрібні, адже алгоритми, прописані в сценаріях ОЖЦ програми, дають універсальні результати, опираючись тільки на питомі показники шуканих компонентів.

У випадку бензинових агрегатів робочою одиницею вимірювання питомої енергозатратності $\epsilon$ "тоннаж-кілометр" (tkm). Під цією одиницею вимірювання позначається кількість тонн, перевезених на одиницю відстані в кілометрах. Для двох бензинових представників це значення приймемо за $1000 \mathrm{tkm}$, що на практиці описуватиметься як 10 т перевезеної ваги на 100 кілометрів шляху. У виборі категорії Процесу ("Processes") вибір припадає на найпоширеніший клас перевезень "Transport, truck 10-20 t".

За рівнем "Low Fluence" вибір припадає на категорію "80 \% LF", як для найчастіше застосовуваної групи транспортних засобів цього класу. Третім транспортним засобом, для якого проводитиметься розрахунок, $\epsilon$ Tesla Semi. Необхідними вихідними даними є питома ємність батарей та запас ходу. Вони становлять 1320 кіловат-годин та 800 кілометрів відповідно.

У розрахунку електричного агрегату використовується непряме прораховування ОЖЦ. Адже на сьогодні не існує на практиці описаних баз даних із потрібними сценаріями та алгоритмами, тому для цього розрахунку одиницею вимірювання буде постачальна електроенергія в Кіловат-годинах $(\mathrm{kWh})$. Встановлене значення є результатом арифметичного розрахунку питомої ємності батарей транспортних засобів цього класу до їхнього запасу ходу. Середнім значенням, еквівалентним для $1000 \mathrm{tkm}$ бензинових агрегатів, становить $165 \mathrm{kWh}$. Категорія процесу - низьковольтна випрямлена електроенергія (Electricity, low voltage) (Cardiagram, 2018).

Для розрахунків використано методику "IMРАCT 2002+ V2.14 / IMPACT 2002+", яка містить на цей час найефективнішу та найширшу базу даних щодо транспорту та енергетики (Introduction, 2018). Вона дає можливість для гнучкого калібрування вихідних даних і пошуку прямих залежностей компонентів системи та вихідних результатів моделювання. Розрахунок проведено за допомогою алгоритму LCA Wizard, який є розробкою компанії "PRé Sustainability". Оскільки його написано спеціально для цього програмного забезпечення, це спрощує роботу і не потребує задіяння стороннього програмного забезпечення та його плагінування до програми.

Результати дослідження та їх обговорення. Результатами проведення моделювання ОЖЦ є декілька типів. Першим і основним є так званий "Мережевий результат" (Network). У цьому режимі обрахунку ми отримуємо мережу забруднювачів, які спрямовуються до одного спільного бала в так званих Impact Points (Бали Впливу). Вони $є$ позасистемною одиницею вимірювання, створеною і описаною розробниками методу "IMPACT 2002+ V2.14 / IMPACT 2002+". Поза межами ОЖЦ вони не мають жодного практичного застосування, але $є$ ідеальними одиницями порівняння впливу на навколишнє середовище, процесів, продуктів та матеріалів, зводячи далекі від порівняння чинники під один знаменник.

Також за допомогою "Network" $є$ змога побачити спрощену схему створення та розподілення викопних та енергетичних ресурсів. Ця схема має практичне застосування для опису складних і детальних технологічних, промислових чи відхідних процесів і показує залежність чинників у вигляді замкненої мережі матерії та енергії.

Результатами цього моделювання стали оцінки в Impact Points:

- 0,0735 Pt (для СВРО-3);

- 0,0649 Pt (для СВРО-5);

- та 0,0424 Pt (для стандарту низьковольтної електровитрати). 
Згідно 3 результатами представленого вище дослідження, математично доведено, що менший вплив на навколишнє середовище здійснюють агрегати на електричній тязі. На практиці це означає, що за умови використання викопного палива для руху транспорту, включаючи усі стадії його перетворення і враховуючи спосіб конвертації викопного палива в електричну енергію, використання електричних агрегатів $\epsilon$ ефективнішим в 1,73 раза порівняно зі стандартом палива СВРО-3 та в 1,53 - порівняно зі стандартом палива СВРО-5, навіть за умови використання ідентичного типу викопного палива.

У перспективі використання альтернативної енергетики ця різниця стане доконанішою, але і за теперішнього рівня технологій електротранспорт все одно залишається ефективнішим 3 точки зору Оцінки Життєвого Циклу.

Другий тип результату називають "Оцінка впливу" (Impact Assessment). У цьому режимі обрахунку отримуємо базу даних із такими категоріями (рис. 1): Канцерогенні неорганічні викиди та скиди; Неканцерогенні неорганічні викиди та скиди; Респіраторні органічні збудники; Респіраторні неорганічні збудники; Токсичність акваторій; Токсичність грунтів; Окиснення грунтів; Окиснення акваторій; Глобальне потепління; Невідновлювальні джерела енергії; Іонізуюче випромінення; Вплив на Озоновий шар; Вичерпання Мінеральних ресурсів. Ці категорії запропонували, створили і описали розробники методу "IMPACT 2002+ V2.14 / IMPACT $2002+"$. Поза межами ОЖЦ вони також не мають практичного застосування.

\begin{tabular}{|c|c|c|c|c|c|}
\hline Se & Impact category & Unit & Truck EU3 & Truck EU5 & \begin{tabular}{|l} 
Truck \\
Electric
\end{tabular} \\
\hline$\Gamma$ & Carcinogens & $\mathrm{kg} \mathrm{C} 2 \mathrm{H} 3 \mathrm{Cl}$ eq & 3,66 & 2,64 & 12,9 \\
\hline $\bar{\nabla}$ & Non-carcinogens & $\mathrm{kg} \mathrm{C} 2 \mathrm{H} 3 \mathrm{Cl}$ eq & 2,36 & 2,34 & 2,8 \\
\hline$\sqrt{v}$ & Respiratory inorganics & $\mathrm{kg}$ PM2.5 eq & 0,262 & 0,181 & 0,123 \\
\hline$\nabla$ & Ionizing radiation & $\mathrm{Bq} C-14$ eq & 41,7 & 41,7 & 200 \\
\hline$\nabla$ & Ozone layer depletion & kg CFC- 11 eq & 3,77E-7 & $3,77 \mathrm{E}-7$ & $1,71 E-5$ \\
\hline$\nabla$ & Respiratory organics & $\mathrm{kg} \mathrm{C} 2 \mathrm{H} 4 \mathrm{eq}$ & 0,0514 & 0,0409 & 0,0253 \\
\hline$\sqrt{\nabla}$ & Aquatic ecotoxicity & kg TEG water & $9,86 \mathrm{E} 3$ & $9,86 \mathrm{E} 3$ & $7,85 \mathrm{E} 3$ \\
\hline$\nabla$ & Terrestrial ecotoxicity & kg TEG soil & $1,87 E 4$ & 1,87E4 & $1,3 \mathrm{E} 3$ \\
\hline$\nabla$ & Terrestrial acid/nutri & $\mathrm{kg} \mathrm{SO} 2 \mathrm{eq}$ & 10,7 & 7,42 & 1,48 \\
\hline 呵 & Land occupation & m2org.arable & $x$ & $\mathrm{x}$ & 0,274 \\
\hline$\sqrt{\nabla}$ & Aquatic acidification & $\mathrm{kg} \mathrm{SO} 2 \mathrm{eq}$ & 1,44 & 1,02 & 0,571 \\
\hline$\nabla$ & Aquatic eutrophication & kg PO4 P-lim & 0,00184 & 0,00184 & 0,0165 \\
\hline$\nabla$ & Global warming & $\mathrm{kg} \mathrm{CO} 2 \mathrm{eq}$ & 171 & 171 & 112 \\
\hline$\sqrt{\square}$ & Non-renewable energy & MJ primary & $2,48 \mathrm{E} 3$ & $2,48 \mathrm{E} 3$ & $1,79 \mathrm{E} 3$ \\
\hline$\nabla$ & Mineral extraction & MJ surplus & 0,0128 & 0,0128 & 2,36 \\
\hline
\end{tabular}

Рис. 1. Таблична інтерпретація категорій

Як видно із наведених даних, між трьома транспортними засобами перевагу має електромобіль над класичним авто стандартів СВРО-3 і СВРО-5. Він програє тільки за такими параметрами, як канцерогени, іонізуюче випромінювання та забруднення акваторій.

Ці результати мають практичне застосування, адже результати обрахунку за методом "IMPACT 2002+
V2.14 / IMPACT 2002+" конвертуються в еквіваленти системи CI. Вибраними еквівалентами $\epsilon$ маса, енергія чи різниця потенціалів поля для кожної із запропонованих категорій. Універсальність такого підходу полягає в можливості зіставлення результатів різних методик моделювання, таких як "Ecological Scarcity 2013 V1.05 / Ecological scarcity 2013", "ReCiPe 2016 Midpoint (I) V1.00" та інші, із наведених в програмі SimaPro 8.

Кінцевим і більш загальним результатом $є$ "Damage Assessment" ("Оцінка небезпеки"). Тут відбувається сегментація за загальними категоріями, а саме: Людське здоров'я; Якість екосистем; Зміна клімату; Ресурси. Математично отримані результати наведено на рис. 2.

\begin{tabular}{l|l|l|l|l|l|l|} 
Se & $\begin{array}{l}\text { Damage } \\
\text { category }\end{array}$ & Unit & Total & Truck EU3 & Truck EU5 & $\begin{array}{l}\text { Truck } \\
\text { Electric }\end{array}$ \\
\hline$\nabla$ & Human health & DALY & 0,000472 & 0,000201 & 0,000141 & 0,00013 \\
\hline$\nabla$ & Ecosystem quality & PDF*m2*yr & 328 & 160 & 156 & 12,5 \\
\hline$\nabla$ & Climate change & kg CO2 eq $^{*}$ & 454 & 171 & 171 & 112 \\
\hline$\nabla$ & Resources & MJ primary & $6,75 E 3$ & $2,48 E 3$ & $2,48 E 3$ & $1,8 E 3$ \\
\hline
\end{tabular}

Рис. 2. Оцінка небезпеки за категоріями впливу

Використовуючи "Damage Assessment", можна побачити цифрове відображення та підсумувати основні висновки проведеного моделювання ОЖЦ. За всіма категоріями очевидною є перевага запропонованої електричної моделі.

Висновки. Отже, за допомогою методу Оцінки Життєвого Циклу аналітично доведено, що вплив на навколишнє середовище автомобілів 3 електричним приводом є значно меншим, ніж автомобілів із класичним бензиновим двигуном. Результати досліджень подано у вигляді таблиць із еквівалентними показниками за сферами впливу на різні категорії навколишнього середовища. Їх можуть використати українські виробники автомобілів. Ця галузь має значний потенціал для впровадження новітніх технологічних рішень, які сприятимуть зниженню використання палива, енергії та створенню екологічного іміджу продукції.

\section{Перелік використаних джерел}

Berzina, S. V., Yareskovska, I. I., et al. (2017). Systema ekolohichnoho upravlinnia: suchasni tendentsii ta mizhnarodni standarty. Posibnyk. Kyiv: Instytut ekolohichnoho upravlinnia ta zbalansovanoho pryrodokorystuvannia. [In Ukrainian].

Frolov, S. M., \& Bilopilska, O. O. (2013). Perspektyvy vykorystannia metodu otsinky zhyttievoho tsyklu v systemi upravlinnia vidkhodamy v Ukraini. Efektyvna ekonomika, 2. Retrieved from: http://www.economy.nayka.com.ua/?op=1\&z=1793. [In Ukrainian].

Introduction. (2018). Introduction to LCA with SimaPro. Introduction Main Tab. Retrieved from: https://www.pre-sustainability.com/download/SimaPro8IntroductionToLCA.pdf

Cardiagram. (2018). Avtomobilnyi forum Cardiagram. Retrieved from: http://cardiagram.com.ua/gruzovik-tesla-review-11199.html. [In Russian].

\section{ИСПОЛЬЗОВАНИЕ SІМАРRО 8 ДЛЯ СРАВНИТЕЛЬНОГО АНАЛИЗА ВЛИЯНИЯ РАЗНЫХ ТИПОВ АВТОМОБИЛЕЙ НА ОКРУЖАЮЩУЮ СРЕДУ}

Осуществлен анализ экологических проблем, которые связаны с автомобильной отраслью, в частности транспортировки. Грамотному принятию решений по улучшению экологических аспектов транспортных средств для государственного или частного бизнеса помогает такой инструмент экологического менеджмента, как Оценка Жизненного Цикла. Этот метод заключается в определении всех факторов влияния на состояние окружающей природной среды на каждом этапе производства продукции. Осуществлены экспериментальные исследования по определению воздействия на окружающую среду автомобилей с бензиновым и электродвигателем благодаря сертифицированной компьютерной программе по экологическому 
моделированию SimaPro 8 в режиме работы "Invenatary". Проведен расчет с помощью алгоритма LCA Wizard, который является разработкой компании "PRé Sustainability". Результатом данного моделирования стали оценки в Impact Рoints, coгласно значениям которых использование электрических агрегатов является более эффективным в 1,73 раза по сравнению со стандартом топлива ЕВРО-3 и в 1,53 - по сравнению со стандартом топлива ЕВРО-5, даже при условии использования идентичного типа ископаемого топлива. Определение влияния на категории, а именно: Здоровье общества; Качество экосистемы; Изменение климата; Ресурсы - помогает осуществить оценку общего влияния на состояние окружающей среды на любой стадии автомобилестроения, эксплуатации и потребления энергоресурсов.

Ключевые слова: Оценка Жизненного Цикла; SimaPro; моделирование; транспортное средство.

Z. S. Odnorih, I. S. Tymchuk, V. I. Zhydun Lviv Polytechnic National University, Lviv, Ukraine

\section{USE OF SIMAPRO 8 FOR COMPARATIVE ANALYSIS OF THE INFLUENCE OF DIFFERENT VEHICLE TYPES ON THE ENVIRONMENT}

The authors have analysed some environmental problems related to the automotive industry, in particular transportation segment. Legislative government force manufacturers are to improve petrol engines in order to reduce toxic emissions, in particular carbon monoxide, nitrogen and sulphur (EURO standards 1-6), as well as the need to find alternative ways to develop transport technologies and perspectives to their use. An environmental management tool such as Life Cycle Assessment helps the competent decision-making on improving the environmental aspects of vehicles for public or private business. This method is original in all the factors affecting the state of the environment at each stage of production. Experimental studies have been carried out on the environmental impact of cars with gasoline engines (EURO-3 and EURO-5) and electric vehicles (Tesla Semi) using the certified SimaPro 8 environmental simulation computer program in the "Inventory" mode. Calculations are made using the LCA Wizard, which is presented by PRé Sustainability. In this calculation mode, a network of contaminants has been obtained. With the help of the "Network" it is possible to look at a simplified table for the creation and distribution of fossil and energy sources. This table has practical application in describing complex and detailed technological, industrial or waste management processes and shows the dependence of factors as a closed network of matter and energy. The results of this simulation were presented at points of impact, the values of which show that the use of electrical aggregates is more efficient in 1.73 compared to fuel EURO-3 and 1.53 compared to fuel Euro-5, even if the use of the same type Fossil fuel. Within the three types of vehicles, the leading model is electric. It loses only by parameters such as carcinogens, ionizing radiation and water pollution. The definition of the impact on the category, such as Health of the society, Quality Ecosystem, the resources, Climate change will help assess the overall environmental impact of any stage of automotive use, operation and energy consumption.

Keywords: Life Cycle Assessment; SimaPro; modeling; vehicle. 